\title{
An Exploration into Pigou's Theory of Cycles
}

\author{
Paul Beaudry *and Franck Portier ${ }^{\dagger}$
}

Revised September 2003

\begin{abstract}
This paper expl ores a theory of business cycl es in whi chrecessions and boons arise due to d ffulties encountered by agents in properly forecasting the econony's future needs in terns of capi $t$ al . The $i$ dea has a l onghi st ory i n the macroeconom c l i terat ure, as refl ectedby the work of $\mathrm{Pi}$ gou [196] The contributi on of this paper is twof ol d First, we i l l ustrate the type of general equil i bri umstructure that can gi ve ri se to suchplenonena. S econd, we exam ne the ext ent to whi chsucha nodel can expl ai $n$ the obs erved pat tern of U S.recessi ons (f requ ency, dept h)wi thut rel yi ng on techol ogi cal regress. We argue that sucha model off recession and of the Asia bunt urns of the 1 ate ni neties.
\end{abstract}

Key Words : Recessions -EquilibriumBusiness Cycl es -Techol og cal Progress Expect at i ons

JEL Classification : E32 -D5

${ }^{*} \mathrm{U}$ ni versity of British Col unbi a, CI AR andNBER.

†U ni versi e'de Toul ou se (CREMAQI DEI -LEERNA, I ns ti tut U ni versi tai re de France andCEPR)

$\ddagger$ The authors wishto thank semi nar partici pants at the Bank of Canad, CREST, CEPREMAP, NBER S u mer I nstitute, NXU, U AB, U BC, U PF, U QAM and U ni versity of Ngo f or their comments. The authrs wouldal so like to thank Nobu Ki yotak i for pointingout an error in a previous daft, two anonynous ref erees and the co-ed t or Mart i n Ei chenbau mf or u s ef ul coments. Thi s res earchi s su pport ed by an S S HCC grant. 


\section{Introduction}

Equilibrium business cycle theory is often criticized on the ground that it does not provide a convincing theory of recession. In particular, it is well known that standard real business cycles models have difficulties explaining recessions t $^{1}$ at least of the size observed in Post War US data- without invoking technological regres: 2 . This criticism is particularly relevant when examining the recession of 2001. Very few economic commentators regard the recession of 2001 as resulting from a negative technology shock. A more common view among economists is that the collapse of investment observed in 2001 resulted from some combination of changes in expectations about the profitability of new investments as well as a possible feedback from a period of very high investment in the late nineties and early in 2000.

The view that recession and booms may arise as the result of investment swings generated by agents' difficulties to properly forecast the economy's need in terms of capital has a long tradition in economic: ${ }^{3}$. For example, this difficulty was seen by Pigou as being an inherent feature of any economy with technological progress. As emphasized in Pigou [1926], when agents are optimistic about the future and decide to build up capital in expectation of future demand then, in the case where their expectations are not met, there will be a period of retrenched investment which is likely to cause a recession. The object of this paper is to offer a formalization of this idea, which we call Pigou cycles, and to explore its quantitative plausibility as a theory of recessions. A key aspect of this paper is to explore the extent to which such a mechanism can explain the depth and frequency of recessions within an equilibrium framework

\footnotetext{
${ }^{1} \mathrm{~S}$ i m l arl y, nom nal -real conf usi on nodels (s ee Lucas [192)generate persistent downt urns onl y if agents' abi l i ty to access pri ce andmoney suppl y i nf ormati on is severel y l i m ted

${ }^{2} \mathrm{~S}$ ee $\mathrm{Kyd}$ and and Prescott [182] or King Pl osser, and Rebel o [1 A not abl e except i on is Ki ng and Rebel o [19 where i t is s bwn that a one sect or busi ness cycl e nodel can expl ai n busi ness cycl es wi thá 1 ow probabi li ty of technol ogi cal regress", provi ded hat we are i n a "li ghs ubsti tuti on economy", charact eri edby $\mathrm{l}$ arge el asti ci ty of $\mathrm{l}$ abor su ppl y andel as ti c capaci ty util i at i on.

${ }^{3}$ Thi s vi ew have been recentl y s u rveyed by De L ong [19] and advocat ed by Bl ack [19 and bruk og u [19]
} 
where technological regress never occurs.

At first glance, the idea of a business cycle model where optimism and pessimism play a dominant role may appear counter to the notion of rational expectations. However, this will not be the case in our model. In effect, we consider an environment where agents get imperfect signals about future productivity growth and use these signals to make decisions about investment; knowing that the received signals are imperfect. The notion of optimism simply refers to a state where agents receive an above average signal. In this environment, periodic recessions are most likely to arise when agents signals about the future are precise. In effect, in our framework, occasional recessions are a sign of a well functioning economy since they reflect the availability of good quality information upon which people act.

The analysis conducted in this paper can be viewed as being complementary to the literature emphasizing how rational herding and information cascades may be important for understanding macroeconomic phenomena (see for example Banerjee [1992], Bickhchandani, Hirshleifer, and Welch [1992], Chamley and Gale [1994], Caplin and Leahy [1993] and Zeira [1994]). In particular, this strand of literature has emphasized how information may occasionally be aggregated improperly thereby leading to significant forecast errors that are shared by a large fraction of the population. The current paper adds to this research program by examining whether (rational/non-systematic) aggregate forecast errors can explain the observed pattern of recessions within a fully-specified dynamic general equilibrium model. It should also be noted that the mechanisms at work in this paper are very close to those discussed in Phelps [1999]. In this sense, this paper can be seen as offering a particular formalization to Phelps idea of structural booms and structural slumps.

The remaining sections of the paper are structured as follows. In Section 2 we illustrate why standard equilibrium models used in the macroeconomic literature do not produce typ- 
ical business cycle co-movements as the result of forecast errors. In Section 3 we present an alternative model, which can be seen as either a three-sectors model or a particular two sector model. We use the model to illustrate how Pigou cycles can arise in this dynamic general equilibrium framework as the result of forecast errors. In Section 4 we evaluate the quantitative properties of this model using standard numerical techniques. The main question addressed here is whether such a model can explain the observed depth and frequency of recession without invoking technological regress. Section 5 examines some of the price implications of the Pigou cycle story and Section 6 offers concluding comments.

\section{Expectation Driven Fluctuations in Standard Equilib- rium Models}

In this section, we want to highlight the type of fluctuations generated by expectations and forecast errors in standard one and two sector equilibrium models. Our main claim is that such models are incapable of generating Pigou cycles, that is they are incapable of generating equilibrium paths in which : (i) a forecast of future technological improvement first leads to a boom defined as an increase in aggregate output, employment, investment and consumption, and (ii) the realization that a forecast is too optimistic leads to a recession defined as a fall in all the same aggregate quantities.

We successively examine a baseline one sector model, a one sector model augmented with capital adjustment costs and a typical two sector model. To most clearly present the properties of these models, we temporarily adopt a non-stochastic framework. This approach has the advantage that the dynamics of the models can be illustrated using impulse response functions to the announcement of a future permanent shocks that is eventually not realized. However, this framework has the disadvantage that forecast errors must be modelled as complete sur- 
prises. This drawback will be remedied in the following section where we embed our model in a stochastic setting where rational agents receive signals, make and revise forecasts, and take decisions, knowing that received signals may be wrong. Our approach is to present the properties of each model using numerical examples. However, as we outline in Appendix 1, the properties emphasized in this section are not sensitive to the particular parameter values used.

\subsection{Expectation Errors in a One Sector Model}

The first model we consider is a simple one sector optimal growth model as used in the RBC literature. The equilibrium dynamics for this model is the solution of the following social planner's program:

$$
\max _{C_{t}, l_{t}, K_{t}} E_{0}\left[\sum_{t=0}^{\infty} \beta^{t}\left\{\frac{C_{t}^{1-\sigma}}{1-\sigma}+v_{0}\left(\bar{l}-l_{t}\right)^{\eta}\right\}\right]
$$

subject to

$$
\left\{\begin{array}{l}
C_{t}+I_{t}=\theta_{t} l_{t}^{\alpha} K_{t}^{1-\alpha} \\
K_{t+1}=(1-\delta) K_{t}+I_{t}
\end{array}\right.
$$

where $C$ stands for consumption, $I$ for investment, $K$ for capital, $l$ for worked hours and $\bar{l}$ for total time endowment. In this model, as well as in the two following ones, the discount rate $\beta$ is set to .98 , the depreciation rate $\delta$ is set to .05 and the intertemporal labor supply elasticity is assumed to be infinite $(\eta=1)$. The share of labor income in total income is assumed to be $2 / 3$, so that $\alpha=2 / 3$. We consider two values for the intertemporal elasticity of substitution in consumption $(1 / \sigma)$, which are $\sigma=1$ and $\sigma=1 / 4$. The reason for considering two values for $\sigma$ is that they give rise to different impact responses for investment and consumption.

The exogenous process we feed into the model aims at capturing the type of expectational phenomena mentioned in the introduction. To this end, at period 1 the following announcement is made: $\theta$ will permanently increase by $1 \%$ in period $t+4$. However, in $t+4$ this technological improvement is not realized, so that the path of technology through the experiment is actually 
constant as individuals make a forecast error about growth.

Figure 1 graphs the response of the one-sector economy to a technological announcement (news) that is eventually not realized. Let us first consider the case $\sigma=1$. The good news instantaneously increases consumption through a wealth effect. As leisure is also a normal good, worked hours decrease, so does output. The only way consumption can be increased while hours are decreased is by decreasing investment: a good news creates an opposite movement in consumption and investment, and causes an output recession that lasts until period 4, when agents realize they were wrong. At that time, this bad news causes a drop in consumption, but a boom in investment, hours worked and output. Obviously, these dynamics do not correspond to what we are calling Pigou cycles. It is nevertheless possible to reverse the initial response of investment by assuming a high intertemporal elasticity of substitution in consumption, which is the case with $\sigma=1 / 4$. However, it is still the case that consumption and investment move in opposite directions: a good news now creates a consumption recession, while the bad news at the time of the revision creates a consumption boom. The induced negative co-movement between consumption and investment can be shown to hold for any set of parameters in such an economy (see the appendix for a proof), and therefore this class of models cannot display Pigou cycles.

\subsection{A One Sector Model with Capital Adjustment Costs}

A natural extension of the above model is to introduce capital adjustment costs in hope of restoring a positive co-movement between consumption and investment. Let us explore this idea by considering a Tobin's $q$ type model, whose equilibrium dynamics is the solution of the following social planner's program: 


$$
\max _{C_{t}, l_{t}, K_{t}} E_{0}\left[\sum_{t=0}^{\infty} \beta^{t}\left\{\frac{C_{t}^{1-\sigma}}{1-\sigma}+v_{0}\left(\bar{l}-l_{t}\right)^{\eta}\right\}\right]
$$

subject to

$$
\begin{cases}C_{t}+I_{t} & =\theta_{t} l_{t}^{\alpha} K_{t}^{1-\alpha} \\ K_{t+1} & =(1-\delta) K_{t}+\Phi\left(\frac{I_{t}}{K_{t}}\right) K_{t}\end{cases}
$$

We assume that the elasticity of $\Phi$ is .5 , and that utility is $\log$ in consumption $(\sigma=1)$.

Figure 2 shows that this extension does not allow the model to generate Pigou cycles. In effect, investment and hours worked do increase on impact, but consumption falls, while the reverse occurs at the time of the expectations revision. Again, it can be shown that this class of economies cannot generate expectational driven booms and bust with a positive co-movement between investment and consumption (see appendix).

\section{$2.3 \quad$ A Typical Two-Sector Model}

We now consider now a simple two sectors optimal growth model. Its equilibrium dynamics is the solution of the following social planner's program:

$$
\max _{C_{t}, l_{c, t}, l_{k, t}, K_{c, t}, K_{k, t}, K_{t}} E_{0}\left[\sum_{t=0}^{\infty} \beta^{t}\left\{\frac{C_{t}^{1-\sigma}}{1-\sigma}+v_{0}\left(\bar{l}-l_{c, t}-l_{k, t}\right)^{\eta}\right\}\right]
$$

subject to

$$
\begin{cases}C_{t} & =\theta_{c, t} l_{c, t}^{\alpha_{c}} K_{c, t}^{1-\alpha_{c}} \\ I_{t} & =\theta_{k, t} l_{k, t}^{\alpha_{k}} K_{k, t}^{1-\alpha_{k}} \\ K_{t+1} & =(1-\delta) K_{t}+I_{t} \\ l_{c, t}+l_{k, t} & \leq \bar{l} \\ K_{c, t}+K_{k, t} & \leq K_{t}\end{cases}
$$

The subscript $c$ stands for the consumption good sector and the subscript $k$ for the capital good sector. The values of the discount rate $\beta$ and the discount factor $\delta$ are the same as before. We take as a benchmark the case of log utility of consumption $(\sigma=1)$ and linear disutility of labor $(\eta=1)$. We assume $\alpha_{c}=.59$ and $\alpha_{k}=.9$ so that, in conjunction with $\theta_{c}=\theta_{x}=1$, the labor share is $2 / 3$ and consumption's share in total output is $75 \%$ at the steady state. Note 
that we are imposing very little decreasing returns to labor in the capital good sector as to potentially allow this sector to react substantially to news.

We successively consider shocks to $\theta_{k}$ and $\theta_{c}$. The response of the economy to these two shocks is presented on Figure 3. Two observations can be made. First, the announcement of a future increase of productivity in the investment sector (an expected increase in $\theta_{k}$ ) moves consumption up, but investment, hours and output down from period 1 to 3 . The opposite is true later on. Again, a good news creates a recession, while the bad one causes an expansion: the model does not display Pigou cycles. Second, the economy does not respond at all to an expected increase in productivity for the consumption sector $\left(\theta_{c}\right)$. This later result comes from the fact that with log preferences, wealth and substitution effect exactly offset following this announcement 4

In order to move away from the knife edge case in the presence of an expected change in $\theta_{c}$, we allow for more or less curvature in the utility of consumption $(\sigma=2$ or $1 / 2)$. As shown in Figure 4, we once again do not obtain from the model a joint increase of consumption, investment, output and hours following a good news, and an aggregate recession following a downward revision of expectations. In effect, we find such a result to be maintained for all plausible configuration of parameters.

In summary, this section has illustrated why standard equilibrium models do not capture the type of dynamics discussed by Pigou. However, this does not imply that it is an impossibility inherent to all general equilibrium models. In effect, in the next section we will present a simple equilibrium model that can support Pigou cycles.

\footnotetext{
${ }^{4}$ The result is similar to what we nouldget in the case of a logutility, Cobb-Doug as-techol og andfulldepreci at i on one sect or nodel. I n thi s configu rati on, one can anal yt i cal l y sol ve the nodel, and prove that 1 abor and the ratio $C / I$ are constant al ong any equilibri umpath Therefore, the econony des not respond to a techol og cal neus.
} 


\section{The Model}

The object of this section is to present what we believe is the simplest dynamic general equilibrium model in which Pigou cycles can arise. The model can be thought as either a three sector model or as a particular two sector model. We will present it as a three sector model.

\subsection{The Production Sector}

The economy is composed of three sectors: a final consumption goods sector, a non-durable goods (or intermediate good) sector and a durable goods sector. The durable good sector is best thought as the construction industry with the stock of the durable good representing plant and housing infrastructure. The final good, denoted $C_{t}$, is produced as CES composite of the nondurable good (or service) $X_{t}$ and the stock of infrastructure $K_{t}$ :

$$
C_{t}=\left(a X_{t}^{\nu}+(1-a) K_{t}^{\nu}\right)^{\frac{1}{\nu}}, \quad \nu \leq 0
$$

The final good $C_{t}$ is a flow of consumption services, which could be modelled as being either produced inside the household (by households purchasing $X_{t}$ and $K_{t}$ ) or in the market. For the sake of concreteness, we choose to treat $C_{t}$ as being produced in the market.

The non-durable good $X_{t}$ is produced using labor according to:

$$
X_{t}=\theta_{x, t} l_{x, t}^{\alpha_{x}} \widetilde{l}_{x}^{\left(1-\alpha_{x}\right)} \quad, \quad 0<\alpha_{x} \leq 1
$$

where $\theta_{x, t}$ is the state of technology in the non-durable goods sector and $l_{x, t}$ is the level of employment in this sector. $\widetilde{l}_{x}$ represents a fixed factor that is required in production. The introduction of the fixed factor assures that overall returns to scale are constant, but forces returns to scale in the variable factor to be decreasing.

The capital good accumulates according to:

$$
K_{t+1}=(1-\delta) K_{t}+I_{t}
$$


where $\delta$ is the rate of depreciation and $I_{t}$ is investment which is provided by the construction sector. Production in the construction sector depends on the state of technology in this sector, $\theta_{k, t}$, the levels of employment $l_{k, t}$ and a fixed factor $\widetilde{l}_{k}$.

$$
I_{t}=\theta_{k, t} l_{k, t}^{\alpha_{k}} \widetilde{l}_{k}^{\left(1-\alpha_{k}\right)} \quad, \quad 0<\alpha_{k} \leq 1
$$

We will restrict attention to cases where the elasticity of substitution between $K_{t}$ and $X_{t}$ in the final goods sector is no greater that one (which seems reasonable given our interpretation of $K_{t}$ as infrastructure). Obviously, both the intermediate good sector and the construction sector should have production technologies which use both physical capital (machines) and labor. However, in order to make our model concise we exclude this possibility and instead introduce fixed factors. This simplifies exposition greatly since it allows us to remain in the family of models with only one capital stock.

\subsection{The Household Sector}

The representative household has preferences defined over consumption of the final good and over the labor supplied in each of the two sectors. The household's objective is to maximize:

$$
E_{0}\left[\sum_{t=0}^{\infty} \beta^{t}\left\{\log \left(C_{t}\right)+v_{0}\left(\bar{l}-l_{x, t}-l_{k, t}\right)\right\}\right]
$$

where $C_{t}$ is the level of consumption of the final good,, $\bar{l}$ is the endowment of labor available in each period, $\beta$ is the discount factor and $v_{0}$ is a positive constant. Note that household preferences are assumed to be separable in consumption and in leisure and that, following Hansen [1985] and Rogerson [1988], we assume that preferences are linear with respect to labor at the representative agent level. The household's within period budget constraint is:

$$
C_{t}+p_{t} I_{t}=w_{x, t}\left(l_{x, t}\right)+w_{k, t}\left(l_{k, t}\right)+r_{t} K_{t}+\Pi_{x, t}+\Pi_{k, t}
$$


where the final good $C_{t}$ is the numéraire, $p_{t}$ is the price of capital, $r_{t}$ is the rental rate of capital, $w_{x, t}$ and $\Pi_{x, t}$ are respectively the wage rate and returns to the fixed factor in the intermediate goods sector, and finally $w_{k, t}$ and $\Pi_{k, t}$ are the wage rate and returns to the fixed factor in the construction sector.

\subsection{Equilibrium}

A Walrasian Equilibrium for this economy is a set of time paths for $k, l_{x}, l_{k}, C, r, p, w_{x}$ and $w_{k}$ such that (1) allocations are optimal given prices (that is, consumers maximize utility and firms maximize profits) and (2) markets clear. Given an initial capital stock $K_{0}$ and processes for $\theta_{x, t}$ and $\theta_{k, t}$, equilibrium allocations for this economy can be found by solving the following social planner's problem:

$$
\max _{C_{t}, l_{x, t}, l_{k, t}, K_{t}} E_{0}\left[\sum_{t=0}^{\infty} \beta^{t}\left\{\log \left(C_{t}\right)+v_{0}\left(\bar{l}-l_{x, t}-l_{k, t}\right)\right\}\right]
$$

subject to

$$
\begin{cases}C_{t} & =\left(a\left(\theta_{x, t} l_{x, t}^{\alpha_{x}} \widetilde{l}_{x}^{\left(1-\alpha_{x}\right)}\right)^{\nu}+(1-a) K_{t}^{\nu}\right)^{\frac{1}{\nu}} \\ K_{t+1} & =(1-\delta) K_{t}+\theta_{k, t} l_{k, t}^{\alpha_{k}} \widetilde{l}_{k}^{1-\alpha_{k}} \\ l_{x, t}+l_{k, t} & \leq \bar{l}\end{cases}
$$

\subsection{Processes for Technology}

Our objective here is to examine whether the above model, once embedded in a stochastic setting with imperfect signals and rational expectations, can display Pigou cycles and mimic some of the quantitative features of recessions; in particular, their frequency and depth. As a simplifying assumption, we will assume that technology grows stochastically only in the nondurable goods sector, while it grows in a deterministic way in the construction sector. This choice appears reasonable given that expectations about technological improvements in the construction sector do not stand out as an important driving force behind business cycles. Moreover, technological improvements in the non-durable goods sector can be interpreted (and 
formalized) as the arrival of new differentiated goods in an economy with tastes for variety. In this interpretation, it is the expected arrival of new goods and its associated infrastructure requirements which would lead a Pigou cycle.

We want to examine an economy where $(i)$ technology only improves (never regresses), (ii) the economy exhibits balanced growth in the long-run and (iii) technological progress is stochastic only in the non-durable good sector. To this end, we assume technology in the construction sector grows deterministically according to

$$
\log \theta_{k, t}=g_{o, k}+g_{1} t
$$

while technology in the intermediate goods sector evolves stochastically according to:

$$
\left\{\begin{array}{l}
\log \theta_{x, t}=g_{o, x}+g_{1} t+\log \widehat{\theta}_{x, t} \\
\log \widehat{\theta}_{x, t}=\lambda \log \widehat{\theta}_{x, t-1}+\varepsilon_{t}, \quad 0<\lambda<1
\end{array}\right.
$$

where $\varepsilon$ is a zero mean i.i.d random variable. We assume that $\varepsilon_{t}$ can either take on a high or a low level. The low level corresponds to the absence of technological progress, which in the case where $\lambda=1$ corresponds to $\varepsilon=-g_{1}$. The respective probabilities of the high and low states are $1-p$ and $p$. With the restriction that $\varepsilon$ has a zero mean, $p$ fully characterizes the distribution of technological innovations. In effect, these restrictions imply that $\varepsilon_{t}$ takes on the value $g_{1} \times p /(1-p)$ in the growth state. When $\lambda$ is very close but smaller than 1 , which will be the case in our simulations $(\lambda=.999)$, this parameterization of $\varepsilon$ guarantees that technological regressions almost never regresses. In effect, we have checked that technology indeed never regresses in our simulations.

\subsection{Information Structure}

Whereas we adopt a process for technology that is fairly standard, we want to depart from the $\mathrm{RBC}$ literature by allowing for a richer informational structure. To this end, in every period 
we allow agents to observe, in addition to $\varepsilon_{t}$, an i.i.d. zero-mean signal $\nu_{t}$. The signal $\nu_{t}$ is assumed to bring new information on the $j$-periods ahead technological innovation $\varepsilon_{t+j}$, for $0<j \leq n$. That is, the signal brings information on the growth of technology between time $t$ and $t+n$. Without loss of generality, the information content of the signals can be summarized by a matrix of correlation between the $\varepsilon_{t+j}$ and $\nu_{t-k}$, where $0<j \leq n$ and $0<k \leq n$. The $(j, k)$ element of the matrix $M, m_{j k}$ represents the correlation between the current signal $\nu_{t-k}$ and the future technological innovation $\varepsilon_{t+j}$.

In every period $t$, given the information set $\left\{\theta_{x}(t-1), \varepsilon_{t}, \nu_{t}, \ldots, \nu_{t-n+1}\right\}$ and the correlation matrix $M$, agents form rational expectations on the sequence of future productivity levels $\widehat{\theta}_{x}(t+j), j>0$. In the following period, given the new information in contemporaneous $\varepsilon$ and $\nu$, expectations on $\widehat{\theta}_{x}(t+1+j), j>0$ are revised. Note that the standard information structure used in most of the literature is a special case of this structure where $\nu_{t}$ is uninformative but nevertheless, given the information revealed in period $t$ by $\varepsilon_{t}$, the expectation on the sequence of $\widehat{\theta}_{x}(t+j), j \geq 1$ is updated every period. In our model, we simply allow the agents to have more information each period than that contained in $\left\{\theta_{x}(t-1), \varepsilon_{t}\right\}$.

A key issue is how best to specify the joint distribution of $\nu_{t-k}$ and $\varepsilon_{t+j}$. Our approach is to favor extreme parsimony in that we would like to summarize the matrix M by one parameter. We choose to restrict the number of parameters this way so that the fit of the model cannot be attributed to simple over-parameterization. Accordingly, we assume that $\nu_{t}$ only brings information on the $n$-periods ahead innovation. In effect, we assume that the signal can take only the values $-g_{1}$ and $g_{1} \times p /(1-p)$, with $q$ being the probability that signal is right about the n-step ahead technological innovation $\left(\nu_{t}=\varepsilon_{t+n}\right)$ and, $1-q$ being the probability that the signal is uninformative in the sense of being an i.i.d. draw on the two states. This process nicely captures the idea that signals may sometimes be entirely void of information, as suggested in 
the herding literature (e.g. Banerjee [1992]). The attractive feature of this process is that it allows the matrix $\mathrm{M}$ to take the following simple form:

$$
\begin{aligned}
& \begin{array}{lllllll}
\nu_{t} & \nu_{t-1} & \ldots & \nu_{t-j} & \cdots & \nu_{t-n+1} & \nu_{t-n}
\end{array} \\
& \left.\begin{array}{c|ccccccc}
\varepsilon_{t+n} & q & 0 & \ldots & 0 & \cdots & 0 & 0 \\
\varepsilon_{t+n-1} & 0 & q & \ldots & 0 & \cdots & 0 & 0 \\
\vdots & \vdots & \vdots & \ddots & \vdots & \ddots & \vdots & \vdots \\
\varepsilon_{t+n-j} & 0 & 0 & \cdots & q & \cdots & 0 & 0 \\
\vdots & \vdots & \vdots & \cdots & \vdots & \ddots & \vdots & \vdots \\
\varepsilon_{t+1} & 0 & 0 & \cdots & 0 & \cdots & q & 0 \\
\varepsilon_{t} & 0 & 0 & \cdots & 0 & \cdots & 0 & q
\end{array}\right)
\end{aligned}
$$

Given the two states process that we have assumed for $\varepsilon$, the economy can therefore go through one of the following four realizations of signal and subsequent growth: a growth signal at time $t$ which is validated by technological growth at time $t+n$ (probability $q(1-p)+(1-$ q) $\left.(1-p)^{2}\right)$; a growth signal at $t$ but no realized growth at time $t+n$ (probability $(1-q) p(1-p)$ ); a no-growth signal at time $t$ but a growth realization at $t+n$ (probability $(1-p)(1-q) p)$; a no-growth signal at time $t$ and a no-growth realization at time $t+n$ (probability $\left.p q+(1-q) p^{2}\right)$. Note that under this information process, the expected levels of technology are weekly increasing over time even though the expected innovations are not necessarily monotonic.

\section{A Quantitative Evaluation of the Model}

\subsection{Calibration}

In our calibration exercise, our goal is not to suggest that a three sector model is a fully adequate description of the economy. In effect, we believe that the above model is an extreme simplification of reality and that it omits many important elements (for example: adjustment costs, variable rates of factor utilization, inventories, additional capital stocks). Nonetheless, we believe that a calibration exercise is useful for evaluating whether the theoretical mechanism by which this model produces booms and recessions (in the absence of technological regress) can 
be considered quantitatively relevant. Hence, we will examine whether a reasonably calibrated version of the model can reproduce the certain observed pattern of recessions - especially frequency and depth - while simultaneously capturing the variances and co-movements emphasized in much of the modern business cycle literature. Throughout this exercise, we will interpret a time period as representing six-months. The reason for adopting a semester as our unit of time is that it allows a decline in output in the model to be referred to as a recession.

There are several parameters in our model, some of which do not have immediate counterparts in the literature. Therefore we approach this calibration exercise by first setting parameters (as is most commonly done) based on known estimates or based on matching certain steady state properties. We estimate the remaining parameters using a simulated method of moments technique. In particular, the discount factor $\beta$ is set equal to .98 , the depreciation rate $\delta$ is set to .05. Total disposable time $\bar{l}$ is normalized to 2 , and the disutility of labor scale parameter $v_{0}$ is set to 1 , so that one third of total time is devoted to work in the steady state. The average growth factor of productivity is set to its observed level in our sample period (see below for a description of the data set). The ratio $\theta_{o, x} / \theta_{o, k}$ and the relative weight of $K$ and $X$ in the CES production function, that is the parameter $a$, are set so that, in conjunction with the other parameters, the labor share is $66 \%$ and consumption's share in total output is $75 \% .5$ We also need to set values for the short-run returns-to-labor parameters $\alpha_{x}$ and $\alpha_{k}$. The literature on scale parameters suggests that the short run returns to labor are close to the labor share in output ${ }^{6}$ However, the literature on the construction industry arrives at a somewhat different conclusion. Allen [1985], for example, estimates the short-run return to labor in construction to be very close to one. In order to reflect these two considerations, we set $\alpha_{x}=.6$ and $\alpha_{k}=.97$,

\footnotetext{
${ }^{5}$ I t s houldbe notedt hat t ot al ou tput (CP)in our nodel is cal cul at edas the su mof the fl ow of cons umpti on servi ces $C_{t}$ pl us the val ue of i nvest nept $\times I_{t}$. The production of the non-durable good is treated as an i nt ermed at e i nput.

${ }^{6} \mathrm{~S}$ ee f or exampl e Burns i de, Ei chenbaum andRebel o [19
} 
that is we impose very little decreasing returns to labor in the construction industry $\left[^{7}\right.$

There remain four parameters that we cannot infer from previous studies, namely the two parameters governing the technology and information processes $(p, q)$, the technological parameter $2^{8}$, and the number of periods $n$ between the arrival of a signal and the related realization of $\varepsilon$. Therefore we choose to estimate these four parameters by Simulated Method of Moments $\left.\right|^{9}$ We implement this procedure by finding, for different values of $n$, a vector $\pi=(p, q, \nu)$ that provides the best match for the following six moments: the volatilities of output, consumption and investment calculated for both the Hodrick-Prescott ( $H P$ filter) cyclical component: ${ }^{10}$ and growth rate $(1-L$ filter $)$. We denote this set of six moment by $M^{o}=\left(\sigma_{y}, \sigma_{c}, \sigma_{i}\right)_{H P, 1-L}$. The HP moments are chosen for reasons of comparability with previous studies, while our interest in "classical cycles" (cycles in terms of growth rate) suggests the use of the $1-L$ filter. Let us denote by $\Omega$ the variance-covariance matrix of these estimators. For a given vector of parameters $\pi$ and $n$, we simulate the model $N$ times for $T$ periods $\left(N=20\right.$ and $\left.T=77^{11}\right)$ and compute a vector of simulated moments $M^{s}(\pi)$. We performed the simulations using a log-linearized approximation of the model (around its (locally) unique steady state). The estimate of $\pi$ is

\footnotetext{
7 Thes e val u es $\mathrm{f} \propto x_{x}$ and $\alpha_{k}$ can al so be justi fiedbas edon sone of the res u l t s f ou ndi n Bu rnsi de, Ei chenbaum andRebel o $[19$

Burnsi de, Ei chenbau mand Rebel o esti nate the short run return to l abor i n du rabl e nanuf act u ri ngto be $\mathbf{8}$ whi l e the cou nt erpart f or non-du rabl e manu f act u ri ngi s es ti nat edt o be 61 (s ee thei r l ast col u ms of Tabl e 10.) $\mathrm{Cl}$ earl y, thes e are esti nates off our cal i brati on.

${ }^{8}$ Note that the paranet er repres ent i ngthe el asti ci ty of substituti on bet ween capi tal andnon-durabl e goods is for the final goods producti on $\mathrm{f} u$ nction. Given that this production f unction descri bes the process of aggregati ng goods and services into a final flow of consumption goods, it does not seemappropriate to set it based on esti nat es deri vedf romi ndustry stud es.

${ }^{9}$ Rou gl y s peak ing si mul at ed method of monents consists of chosingthose mod parameters val ues that produce the best natchbetween a set of emi rical andsi mulatednoments, where the d stance between those noments is eval uatedusingthe i nverse of a consistent esti nate of the monents esti nat ors as ympt otic vari ance nat rix. See Duffiand Sing et on [19] f or an exposition and Hault, Langot, and Porti er [19]f or an appl i cati on.

${ }^{10} \mathrm{I} \mathrm{n}$ cal cul at i $\mathrm{hg} P$ fil tered noments we set $\lambda=00 \mathrm{si}$ nce thi s appeared to gi ve reas onabl e cycl i cal components to other semestrial data.

${ }^{11} T 77$ corres ponds to the lengt hof our sample.
} 
then

$$
\widehat{\pi}=\operatorname{Arg} \operatorname{Min}_{\pi} \quad J=\frac{N T}{N T+1}\left(M^{s}(\pi)-M^{o}\right) \Omega\left(M^{s}(\pi)-M^{o}\right)^{\prime}
$$

We estimated a $\pi$ vector for each of the ten cases where $n$ was allowed to vary between 1 and 10. We then chose $n$ and the corresponding $\pi$ vector based on the lowest value for the $J$ statistic.

The data we use are US National Income and Product Account data covering the period 1959 to the end of 1997 . We build the relevant empirical counterparts to our theoretical constructs in the following manner. Durable goods and inventories are considered investment, and net exports are split into consumption and investment according to the relative share of consumption and investment. More precisely, the three series are constructed as follows: Investment $(I)=$ Fixed investment + Durable goods + Change in business inventories + Net export of good and service $\times(i / y)$, Consumption $(C)=$ Nondurable goods + Services + Net export of good and service $\times(c / y)$, Output $(Y)=$ Consumption + Investment. Variables are then expressed in per capita terms. Estimation results for the case where $n=2$ (which corresponds to a minimum for the $J$ statistic) ${ }^{12}$ are given in Table 1, and the model's predictions relative to the targeted moments are given in Table 2 .

Table 1: SMM Estimators of $p, q$ and $\nu$ (standard-deviations in parenthesis)

\begin{tabular}{cc}
\hline \hline$p$ & $71(04)$ \\
$q$ & $82(31)$ \\
$\nu$ & $-378(121)$ \\
$n$ & 2 \\
\hline$J$ & 330 \\
$\chi^{2}(2)$ at 9 & \\
\hline \hline
\end{tabular}

The results from the estimation using simulated method of moments implies an economy where $(i)$ infrastructure $K$ and other goods $X$ are strong complements (elasticity of substitution

\footnotetext{
${ }^{12}$ We $\mathrm{d}$ d not find any si gni ficant $\mathrm{d}$ ff $J$ cal cul at edusing 1 or $n=$. bnever, the val ue of $\quad J$ bes i ncrease substantial l yrf or 2 .
} 
Table 2: Targeted and Simulated Moments

\begin{tabular}{clc}
\hline \hline & U S.Dat a & nodl si mul ation \\
$\sigma_{c}(H P)$ & 105 & \\
$\sigma_{c}(1-L)$ & $0687(05$ & \\
$\sigma_{y}(H P)$ & $2162(222)$ & 1825 \\
$\sigma_{y}(1-L)$ & $1438(125$ & \\
$\sigma_{i}(H P)$ & $6872(669$ & 5 \\
$\sigma_{i}(1-L)$ & $40(488)$ & 5 \\
\hline \hline
\end{tabular}

close to .2), (ii) agents receive rather informative signals, that is, signals are right $82 \%$ of the time, (iii) technological growth is quite sporadic with $71 \%$ of semesters registering no technological progress and $29 \%$ percent of semesters registering growth of $4.17 \%$, and $(i v)$ the delay between signals and realizations is one year (2 periods or semesters). It is interesting to note that, under the null that the model is the Data Generating Process and that $n=2$, the $J$ statistics (which conditional on $n$ would follow a $\left.\chi^{2}(3)\right)$ cannot be rejected at a $5 \%$ level $\left(\chi^{2}(3)\right.$ at $95 \%$ is 7.8). Although this is not an appropriate test since we are choosing $n$ to minimize $J$ (in which case it is more appropriate to compare $J$ with a $\chi^{2}(2)$ distribution), it nevertheless suggests that this simple three sector model can fit these data surprisingly well.

\subsection{A First Look at the Model's Quantitative Properties}

We illustrate here key properties of the model using impulse response functions derived from our quantified version of the model. However, it should be noted that most of the key properties of the equilibrium dynamics can be derived analytically, and are not dependent on the particular values derived above.13.

Transitional Dynamics : In Figure 5, we plot the transitional dynamics of our model when the capital stock begins at $1 \%$ below its steady state. Figures 5 shows that employment in the construction sector begins above its steady state and gradually converges to it, which allows

\footnotetext{
${ }^{13} \mathrm{~S}$ ee the work ing paper versi on of this work (Beau dy andPorti er [1 190 or nøre det ai l s.
} 
capital to be built up. During this transition, employment in the non-durable goods sector is below its steady state level, as some labor resources are shifted to the construction sector.

There are two more aspects to notice from Figure 5. First, along the transition path, the aggregate level of employment (as defined by $l_{x}+l_{k}$ ) could be either above or below its steady state level, depending on the values of the parameters. Second, these dynamics are qualitatively similar to those derived for the one sector model generally used in real business cycle models. However, the dynamics of this model will differ from those of the more standard model when anticipated technological change is introduced.

Expectationally Driven Booms and Busts : Let us now turn to examining how such an economy responds to an anticipated increase in technology in the consumption good sector, as induced by a positive realization of the signal $\nu_{t}$. As a result of the signal, a technological improvement is expected to arise at period 4.

Figure 6 reports the dynamics associated with the case where the expected increase is actually realized. As can be seen from the figure, employment in the construction sector immediately jumps, then continues to increase until period 4. At this point technology improves and employment in the construction sector jumps on to the new saddle path, and then gradually decreases to its steady state level while the capital stock continuously increases. These dynamics are such that anticipated technological improvement can be said to cause an expectation lead boom, that is, from period 1 to 3 , employment in both sectors, total output (defined as $C_{t}+p_{t} I_{t}$ ), investment and consumption are all increasing even though technology has not yet improved.

Let us now consider what happens if, at period 4, instead of technology improving as anticipated, individuals learn that their forecast is incorrect and that technology does not actually change (it remained at its initial level). In this case, there is a fall in output and 
employment in the construction sector at period 4, as individuals realize that they previously over-accumulated. Following this drop, employment gradually returns to its previous steady state as the capital stock returns to its initial level. Figure 7 graphs the time paths of all the main variables through this entire sequence of anticipation and realization.

Note from Figure 7 that the economy first experiences a boom and then a recession without ever having experienced an actual change in technology. In particular, at period 4 aggregate output, investment and employment all fall, while consumption falls with a lag. It is interesting to note the pattern of investment prices $(p)$ that decentralizes this behavior (shown on Figure 8). During the first phase, from period 1 to period 4, individuals invest in infrastructure in anticipation of realizing capital gains. Throughout this phase, the price of infrastructure increases thereby fulfilling these expectations of capital gains. At period 4, however, the price of infrastructure falls in recognition of an over-supply. The new low price for infrastructure makes investment unprofitable and therefore employment in the construction industry collapses. As the oversupply of capital slowly diminishes due to depreciation, incentives for new investment reemerge and thereby pulling the economy out of the recession.

Discussion and policy implications In our view, these dynamics capture the idea, suggested by Pigou and others, that forecast errors may be key in understanding recessions. In effect, in this model, a boom and a recession can arise as the result of overly optimistic expectations about future technological growth. Two questions arise immediately. Which properties of this model (in comparison to more standard ones) allows it to generate Pigou cycles, and are these properties reasonable? A model will generate Pigou cycles if (a) when agents get a signal that productivity will be probably be high in the future, they increase their demand for investment and (b) this increase in investment good demand is met by an increase in labor supply, not 
a decrease in consumption. Point (a) is well understood and accounted for in standard models. In a one-sector model with reasonable intertemporal elasticity of substitution in consumption, adjustment costs to capital are sufficient to account for an investment boom. In a two-sector model, it is needed that the future shock improve productivity in the consumption good sector. Otherwise, it is optimal for the agent to wait for the realization of the shock to start producing capital goods. In our model, enough complementarity is needed for investment to start raising with the news. If capital and the non durable good were substitutable enough, agents would decide to wait until the arrival of the shock, then reallocate labor from the non durable sector to the newly more productive capital good sector, and substitute non durable good for capital to maintain their flow of consumption. To confirm that this mechanism is indeed the one at work, one can show (figures not reported) that (i) in our model with Cobb-Douglas production function $\left(C_{t}=X_{t}^{a} K_{t}^{1-a}\right)$, the economy does not respond to a news (all responses are flat until the arrival of the technological improvement), and (ii) consumption, hours and investment go down if the news signals a technological improvement in the capital good sector.

We think that point (b) is specific to our model. The key property that allows this model to generate Pigou cycles is the fact that current consumption decisions in the model are decoupled from current investment decisions. That is, agents in the economy can determine how much investment in infrastructure to undertake without this decision having a direct feedback on how much the economy can currently consume. In other words, the shadow price of investment in the above three sector model is not directly related to foregone consumption but only relates to the cost of reduced leisure for workers in the construction industry. The fact that increased investment is not directly reducing consumption possibilities is a property that may be a sensible description of short-term substitutability constraints in a modern economy. For example, if an economy has an oversupply of buildings, it seems a reasonable simplification to exclude- at least 
in the short run -the possibility of immediately transforming the output of construction sector workers into others goods. It is this type of constraint which differentiates the above three sector model from more standard macro models and thereby allows for Pigou cycles. Having high enough labor supply elasticity is important for decoupling investment and consumption decisions. Agents that value smoothness of leisure time would be less likely to work harder in both sector at the time of the news. If we consider a version of our model with non infinite intertemporal elasticity of labor supply $\left(\log \left(C_{t}\right)+v_{0} \log \left(\bar{l}-l_{x, t}-l_{k, t}\right)\right)$, we observe (figure not reported) an increase in investment and $l_{k}$ on impact, but a decrease in $l_{x}$ and therefore a small decrease on impact of consumption. After one period, consumption increases and passes above its steady state level, even though no technological improvement is observed yet.

It is interesting to conjecture how individuals may perceive a downturn generated by a Pigou cycle and how this may lead them to choose inappropriate policies. For example, at the onset of a recession, individuals in our model are likely to perceive the cause of the recession as being a fall in aggregate demand. In response, they may be tempted to favor policies, that would stimulate investment demand; such as temporary tax breaks or investment tax credits. However, such policies would be misplaced in this model since it is precisely an excess of investment that caused the recession. Policies which stimulate investment may even appear to individuals as a cure to downturns — since they would temporarily increase employment and output - when in fact such policies would at best be a postponement of needed adjustment.

\subsection{Does the Model Produce Sizable Recessions?}

In this section we explore the extent to which our model economy is capable to generate recessions. To this end, summary business cycle statistics and a set of recession statistics for the U.S. economy are given in Tables 3 and 4. Our construction and reporting of recession 
statistics, in addition to standard business cycle statistics, reflect our desire to evaluate the capacity of our model to explain this particular phase of the cycle.

Table 3: Statistics on Recessions (U.S. NIPA, 59:1-97:2, semi-annual)

\begin{tabular}{cccccc|}
\hline \hline$\overline{\Delta^{-} y}$ & $F\left(\Delta^{-} y\right)$ & $\overline{\Delta^{-} c}$ & $F\left(\Delta^{-} c\right)$ & $\overline{\Delta^{-} i}$ & $F\left(\Delta^{-} i\right)$ \\
-11 & 19 & & & & \\
$(2)$ & $(5$ & & & \\
$\min \left(\Delta^{-} y\right)$ & $\min \left(\Delta^{-} i\right)$ & $\min \left(\Delta^{-} c\right)$ & $\left.\overline{\Delta c}\right|_{\Delta y<0}$ & $\left.\overline{\Delta i}\right|_{\Delta y<0}$ \\
-25 & - & - & $(17)$ & $(79$ \\
- & - & & \\
\hline \hline
\end{tabular}

Table 4: Statistics on Business Cycle (U.S. NIPA, 59:1-97:2, semi-annual)

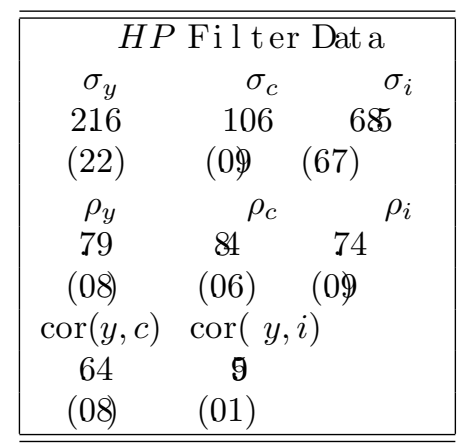

In these two tables, the figures in parenthesis are standard deviations of estimators. In Table 3, the variables of the form $\overline{\Delta^{-} x}$ represents the average growth rate of $x$ conditional on $\Delta x$ being negative, $F\left(\Delta^{-} x\right)$ represents the percentage of semesters for which $\Delta x$ is negative, $\min \left(\Delta^{-} x\right)$ represents the largest recession (percentage decrease) of $x$, and finally $\left.\overline{\Delta x}\right|_{\Delta y<0}$ is the average growth rate of $x$ conditional on $\Delta y$ (growth in aggregate output) being negative. Note that recessions are not rare events: almost one fifth of semesters experienced output drops and on average the falls are $1.1 \%$. For investment, recessions happen one third of the time, and the average fall in a semester is almost $4 \%$. In contrast, recession for consumptions happen rarely and when they do happen they are on average very shallow at .1\%.

Let us now turn to the statistics generated by the model. We evaluate the model's ability to 
match the data in the following way. We generate 1000 simulations of length 77 (the number of observations in our sample), and compute the mean and the standard deviations of the moments of interest. We then ask the question: "Is the data at odds with the statistics generated by the model?". We ask this question for several different moments, focusing on one moment at a time. Tables 5 and 6 report statistics generated by the model, with standard deviations given in parenthesis. $\mathrm{A} \star$ on a statistic indicates that the empirical moment lies within a interval of \pm 2 standard deviations around the mean of the model simulations $(\star \star$ for \pm 3 standard deviations). We interpret this as follows: as far as this particular moment is concerned, we cannot reject that the data could have been generated by our model.

Table 5: Statistics on Recessions (Model)

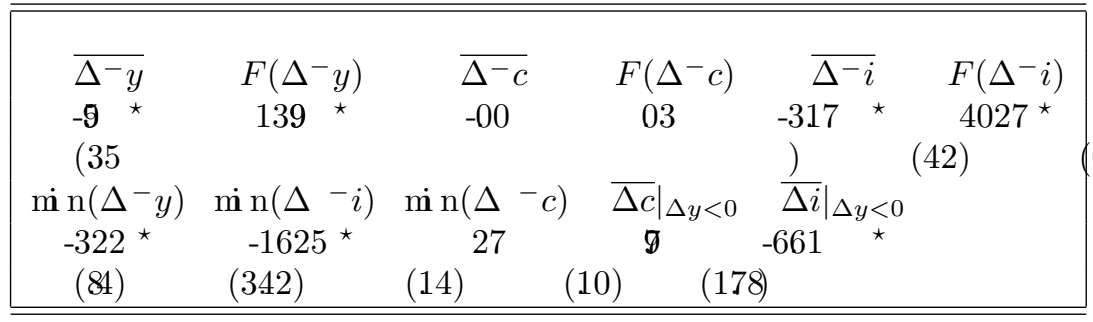

Table 6: Statistics on Business Cycle (Model)

\begin{tabular}{|cccc|}
\hline \hline \multicolumn{4}{c|}{$H P$ fil teredDat a } \\
$\sigma_{y}$ & $\sigma_{c}$ & $\sigma_{i}$ \\
$15^{\star}$ & $107^{\star}$ & $5^{\star}$ \\
$(27)$ & $(18)$ & $(80)$ & \\
$\rho_{y}$ & $\rho_{c}$ & $\rho_{i}$ \\
$67^{\star}$ & $8^{\star}$ & $5^{\star}$ \\
$(09$ & $(05$ & & \\
$\operatorname{cor}(y, c)$ & $\operatorname{cor}(y, i)$ & \\
$63{ }^{\star}$ & $\Phi$ & \\
$(06)$ & $(01)$ & \\
\hline \hline
\end{tabular}

We first comment on the ability of the model to reproduce standard business cycle statistics as reported in Table 6. Recall that the model has been calibrated to give a good fit for the standard deviations of $\mathrm{HP}$-filtered output, consumption and investment. However, the model 
was not calibrated to match the other statistics in Table6. In particular, it is interesting to note that the serial correlations and cross correlation of the $H P$ filtered data are well reproduced by the model. We interpret these results as suggesting that the model does a good job at matching the moments most often discussed in the $R B C$ literature. Let us now look at recession statistics (Table 5). Again recall that the calibration has been done without targeting these statistics. As far as output and investment are concerned, the model does a very good job at reproducing the recession statistics. Average and maximum depth of recessions, as well as frequency of recessions, are all matched by the model even though there is never technological regress. The only major failure of the model is that consumption is too smooth: in effect, the model does not produce significant recessions in per capita consumption, it only produces significant slowdowns. However, we do not interpret this failure of the model to be a fatal drawback given that drops in consumption are also rare and small in the data (see Table 3).

In order to get an additional view of the model's ability to reproduce observed output growth, Figure 9 plots the histogram of output growth. As can be seen from the Figure, the empirical histogram lies almost entirely within the 2 standard deviations bands associated with the histogram generated by the model. This figure nicely illustrates how a simple three sector equilibrium model without any technological regress can reproduce important patterns of output growth.

\section{Asset Prices Implications}

Our model has sharp implications for the price of capital. In effect, if one believes that fluctuations are largely driven by expectations of technological improvements then, as illustrated previously on Figure 8, the relative price of capital should co-vary positively with changes in output that are induced by such expectations. In this section we want to explore the relevance 
of our model along this dimension. To do so, we proceed in two steps. First, we examine some un-conditional correlations between output and the price of capital. Second we report some conditional correlations and impulse responses inferred from a VAR using long run restrictions. The advantage of the second approach is that it allows us to examine more closely properties of the data that can be tied directly to changes in technological opportunities. However, before going to the data, we need to identify what is meant by the price of capital in our model. In accordance with the spirit of the model, we will focus on three price indices for capital. The first two measures derive naturally from the idea that the capital stock in our model is the infrastructure built by the construction industry. For this reason we will use both the price of residential investment and the price of nonresidential buildings as measures of the price of capital. However, in order to allow for a larger definition of capital, we will also examine the behavior of a stock market index as given by the Standard \& Poors 500 14 .

\subsection{Unconditional correlations}

When we consider the Standard \& Poors 500 as our measure of the price of capital, we obtain a positive correlation of .33 between H-P filtered output and price data for the U.S. postwar period. When we consider the price of residential investment as our measure of the price of capital, we obtain a correlation of .33. Finally, when we consider the price of non-residential buildings as the relevant price, we obtain a correlation of .29.15 Although these correlations are not exceedingly high, they do support the predictions of the model. One reason for why these

\footnotetext{
${ }^{14}$ Our sampl e runs quarterly from198 to 20004. The vari abl es that we use here are obtai nedf romthe U S.BEA. The i mpl i ci t pri ce defl at or (hereafter I PD) of nonresi dential build ngs and the I DP of residential i nvestment are $d$ vi ded by the I PD of nondurabl e goods to obtai n rel ati ve pri ces. Output is neas u redas the Non FarmPri vate Busi ness Sector Goss Donesti c Product. When computing correl ati ons, seri es are fil tered u s i ng Wdi ck -Prescott fil ter wi th 1600 .

15 Nonresidential build ngs constitutes about two th rds of the broadcategry ref erredto struct u res. Whever, we shuldnote that the price of non-resi dential buildngs behaves substantially d ff components i n struct u res wi chare mi ni ngexpl orati on, shaf ts, wel l s andutili ti es. I n parti cul ar, these 1 ast thee components have asli ght negat i ve covari ance wi thoutput.
} 
correlations may not be as high as would be predicted by the model is that fluctuations in the data are likely induced by many sources of shocks, not just the ones considered in the model. In order to explore this possibility, we now turn to examining some conditional moments.

\subsection{Conditioning}

If we interpret our model broadly, it actually should be viewed as delivering predictions for conditional correlation, as it predicts that the relative price of capital increases when the economy is hit by expected but permanent shocks to technology. To get an estimate of this conditional correlation from the data, we estimate bivariate VARs $(\Delta y, \Delta p)$ where $y$ is the log of output and $p$ the $\log$ of a relative price of capital ${ }^{16}$. The series used are the same as those used to compute unconditional correlations. From the estimated VAR, we compute the responses to the permanent shock to output17. The VAR analysis is repeated for the price of residential investment, the price of nonresidential buildings and the stock price index. Impulse response functions to a permanent shock are displayed in Figure 10, together with $90 \%$ confidence bands. The impact responses of residential investment, nonresidential buildings prices and stock market index are all significantly positive. When we compute the correlation between output and price along the response paths we obtain a conditional correlation is 0.89 for residential investment price, 0.79 for nonresidential buildings and 0.75 for the stock price. These correlations bring substantial support for the type of mechanism we have illustrated.

\footnotetext{
${ }^{16} \mathrm{Al} 1 \mathrm{ARs}$ are esti natedwi th5 the $\mathrm{S} \& 5$ these two vari abl es is hi ghl y pl ausi bl e.

${ }^{17}$ Formal $1 \mathrm{y}$, i $\mathrm{n}$ the s pi ri t of $\mathrm{Bl}$ anchard and Quah [1\$ we i dent ify two orthognal shock s to the bi vari ate system One is restrictedto have ero longrun i mact on the level of out put. The ot her one is our pernanent shock. I t is i ndeeda pernanent shock, as the series are al l non stati onary.
} 


\section{Conclusion}

In this paper we have illustrated an equilibrium business cycle model where anticipations and realizations of technological growth were qualitatively and quantitatively able to explain several patterns associated with business cycles and recessions. We think that the mechanism

of this model - the importance of forecasts and forecast errors in explaining aggregate movements of activity - may help understand certain episodes of cyclical downturns in industrialized economies. In particular, this type of model may provide a useful framework for understanding the recent downturns in South-East Asia since it has been argued that revisions of expected growth were central in generating the crises observed in these economies. The recent U.S. recession of 2001 can also be possibly understood as the downturn of a Pigou cycle. In effect, most people think that the 1990's boom was induced by the perception of big future technology shifts in the durable good sector. Our model does not introduce two types of capital goods, and this perceived technological shift would need to be interpreted as an improvement in the $X$ good sector, not in the capital good one, capital standing here for infrastructures, not equipment. However, we leave a detailed exploration of these particular episodes for future research.

\section{References}

Allen, S. (1985): "Why Construction Industry Productivity is Declining?," Review of Economics and Statistics, 67, 661-69.

BAnerJeE, A. (1992): "A Simple Model of Herd Behavior," Quarterly Journal of Economics, 107, 797-817.

Beaudry, P., And F. Portier (1999): "An Exploration into Pigou's Theory of Cycles," mimeo, University of Bristish Columbia and Université de Toulouse, CEPR Discussion Paper 
2996, October 2001.

BickhChandani, S., D. Hirshleifer, and I. Welch (1992): "A Theory of Fads, Fashion, Custom, and cultural change as Informational Cascades," Journal of Political Economy, 100, 992-026.

Black, F. (1995): Exploring General Equilibrium. MIT Press, Cambridge, Mass.

Blanchard, O., And D. Quah (1989): "The Dynamic Effects of Aggregate Demand and Supply Disturbances," American Economic Review, 79(4), 655-673.

Burnside, C., M. Eichenbaum, and S. Rebelo (1995): "Capital Utilization and Return to Scale," NBER Macroeconomics Annual 1995, pp. 67-109.

Caplin, A., And J. LeAhy (1993): "Sectoral Shocks, Learning and Aggregate Fluctuations," Review of Economic Studies, 60, 1065-85.

Chamley, C., And D. Gale (1994): "Information Revelation and Strategic Delay in a Model of Investment," Econometrica, 62(5), 1065-85.

De Long, B. (1991): "Liquidation" Cycles and the Great Depression," mimeo, Harvard University.

Duffie, D., And K. Singleton (1993): "Simulated Moments Estimators of Markov Models of Asset Prices," Econometrica, 61(4), 929-52.

Greenwood, J., S. Herkowitz, and P. Krusell (1997): "Long-Run Implications of Investment-Specific Technological Change," American Economic Review, 87(3), 342-62.

Greenwood, J., And M. Yorukoglu (1997): “1974,” Carnegie-Rochester Conference Series on Public Policy, 46(1), 49-95. 
Hairault, J., F. Langot, and F. Portier (1997): "Time to Implement and Aggregate Fluctuations," Journal of Economics Dynamics and Control, 22, 109-21.

Hansen, G. (1985): "Indivisible Labor and the Business Cycles," Journal of Monetary Economics, 16(3), 309-327.

King, R., C. Plosser, and S. Rebelo (1988): "Production, Growth and Business Cycles I," Journal of Monetary Economics, 21(2/3), 196-232.

King, R., and S. Rebelo (1999): "Resuscitating Real Business Cycles," in Handbook of Macroeconomics, ed. by J. Taylor, and M. Woodford, vol. 1C. North-Holland.

Kydland, F., and E. Prescott (1982): "Time to Build and Aggregate Fluctuations," Econometrica, 50(6), 1345-1370.

LuCAS, R. (1972): "Expectations and the Neutrality of Money," Journal of Economic Theory, 4(2), 103-124.

Phelps, E. (1999): "Behind this Structural Boom: The Role of Asset Valuations," American Economic Review, 89(8), 63-68.

Pigou, A. (1926): Industrial Fluctuations. MacMillan, London.

Rogerson, R. (1988): "Indivisible Labor, Lotteries and Equilibrium," Journal of Monetary Economics, 21(1), 3-16.

Zeira, J. (1994): "Informational Cycles," Review of Economic Studies, 61(1), 31-44. 


\section{Appendix}

\section{A Proof of the Impossibility of Pigou Cycles in Standard One-Sector Models}

In this appendix we prove that, in a one-sector economy with or without adjustment cost to capital, Pigou cycles cannot occur, i.e. we cannot have positive co-movements of consumption, investment and hours induced by an expectational change without any change to current fundamentals.

Let us first describe the environment. The economy is competitive, populated with one representative firm and one representative household. Preferences are ordered by

$$
E_{0} \sum_{t=0}^{\infty} \beta^{t} U\left(C_{t}, L t\right)
$$

where $U$ is a twice continuously differentiable utility function and $\beta \in] 0,1[$. In particular, we assume that $U_{C}>0$ and $U_{C C}, U_{L L}, U_{C L}<0$, which implies that leisure is a normal good. In order to provide a general characterization, it is helpful to specify the production set as follows:

$$
C_{t}=G\left(K_{t}, X_{t} L_{t}, I_{t}\right)
$$

where $L_{t}$ is labor input, $K_{t}$ is the capital stock, $X_{t}$ is an index of technology, $I_{t}$ is investment and where $G$ is a twice continuously differentiable constant return to scale function with $G_{I}<0$. For our two cases of interest, the function $G$ take the following forms.

In the case corresponding to the standard one sector model:

$$
G\left(K_{t}, X_{t} L_{t}, I_{t}\right)=F\left(K_{t}, X_{t} L_{t}\right)-I_{t}
$$

with $F_{1}, F_{2}, F_{12}>0$ and $F_{22}, F_{11}<0$. The second case corresponds to a model with adjustment costs:

$$
G\left(K_{t}, X_{t} L_{t}, I_{t}\right)=F\left(K_{t}, X_{t} L_{t}\right)-\Psi\left(\frac{I_{t}}{K_{t}}\right) K_{t}
$$

with again $F_{1}, F_{2}, F_{12}>0$ and $F_{22}, F_{11}<0$, and where $\Psi$ is a convex function. The important aspect to remember about these two cases is that $G_{L I}$ is equal to zero.

Capital accumulates over time according to the following law of motion

$$
K_{t+1} \leq(1-\delta) K_{t}+I_{t}
$$

with $0<\delta<1$. As we consider convex economies with perfect competition, the two theorems of welfare hold, and we can obtain equilibrium allocations from the following social planner's program:

$$
\begin{array}{r}
\max _{\left\{C_{t+j}, K_{t+j+1}, L_{t+j}\right\}} E_{t} \sum_{j=0}^{\infty} \beta^{t} U\left(C_{t+j}, L_{t+j}\right) \\
\text { s.t. }\left\{\begin{array}{l}
C_{t+j}=G\left(K_{t+j}, X_{t+j} L_{t+j}, I_{t+j}\right) \\
K_{t+j+1}=(1-\delta) K_{t+j}+I_{t+j} \\
K_{t+j} \text { given }
\end{array}\right.
\end{array}
$$

At any given period $t$, the first order conditions of the problem are given by

$$
\begin{aligned}
U_{C}(t) X_{t} G_{L}(t) & =-U_{L}(t) \\
C_{t} & =G\left(K_{t}, X_{t} L_{t}, I_{t}\right) \\
-G_{I}(t) U_{C}(t) & =\beta E_{t}\left[U_{C}(t+1)\left(G_{K}(t+1)-(1-\delta) G_{I}(t+1)\right)\right] .
\end{aligned}
$$


We now want to explore the conditions under which a change in expectations - without a current change in $X_{t}$ - necessarily leads to a negative co-movement between $C_{t}$ and $I_{t}$. To derive such a condition, all that is needed is to examine the determinants of $\frac{d C}{d I}$ implicitly defined by equations A.4 and (A.5), since these two equations define the set of temporary equilibria.

This derivative is given by:

$$
\frac{d C}{d I}=\frac{G_{I}+G_{L} \kappa_{3}}{1-G_{L} \kappa_{1} \kappa_{2}}
$$

where

$$
\left\{\begin{array}{l}
\kappa_{1}=-\left(G_{L} U_{C L}+U_{C} G_{L L}+U_{L L}\right)^{-1}>0 \\
\kappa_{2}=G_{L} U_{C C}+U_{L C}<0 \\
\kappa_{3}=U_{C} G_{L I} \lesseqgtr 0 .
\end{array}\right.
$$

From this derivative, we can immediately note that if $G_{L I} \leq 0$ then $\frac{d C}{d I}<0$. Hence, it is necessarily the case that, within the standard one sector model with or without adjustment costs to capital, an expected change in future technological opportunities leads to a negative co-movement between $C_{t}$ and $I_{t}$ since both these models have the property that $G_{L I} \leq 0$. Note that it is easy to verify that for the three sector model we present in the paper, the implied $G$ function has $G_{L I}>0$. 


\section{B Figures related to Section 2}

Figure 1: Response of the one-sector economy without capital adjustment costs to an announcement at time 1 of future positive shock on the technology and no realization of that shock at time 4
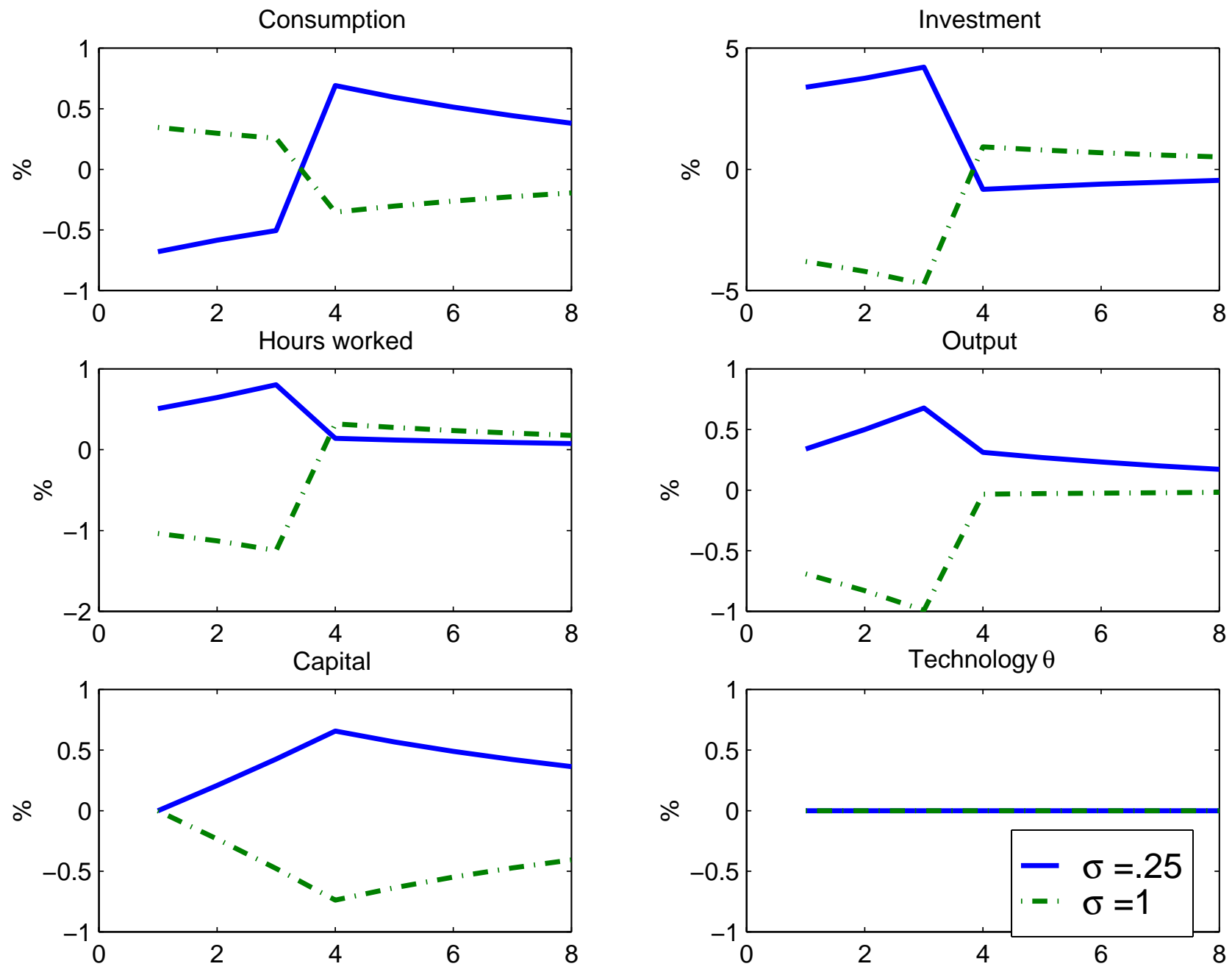
Figure 2: Response of the one-sector economy with capital adjustment costs to an announcement at time 1 of future positive shock on the technology and no realization of that shock at time 4
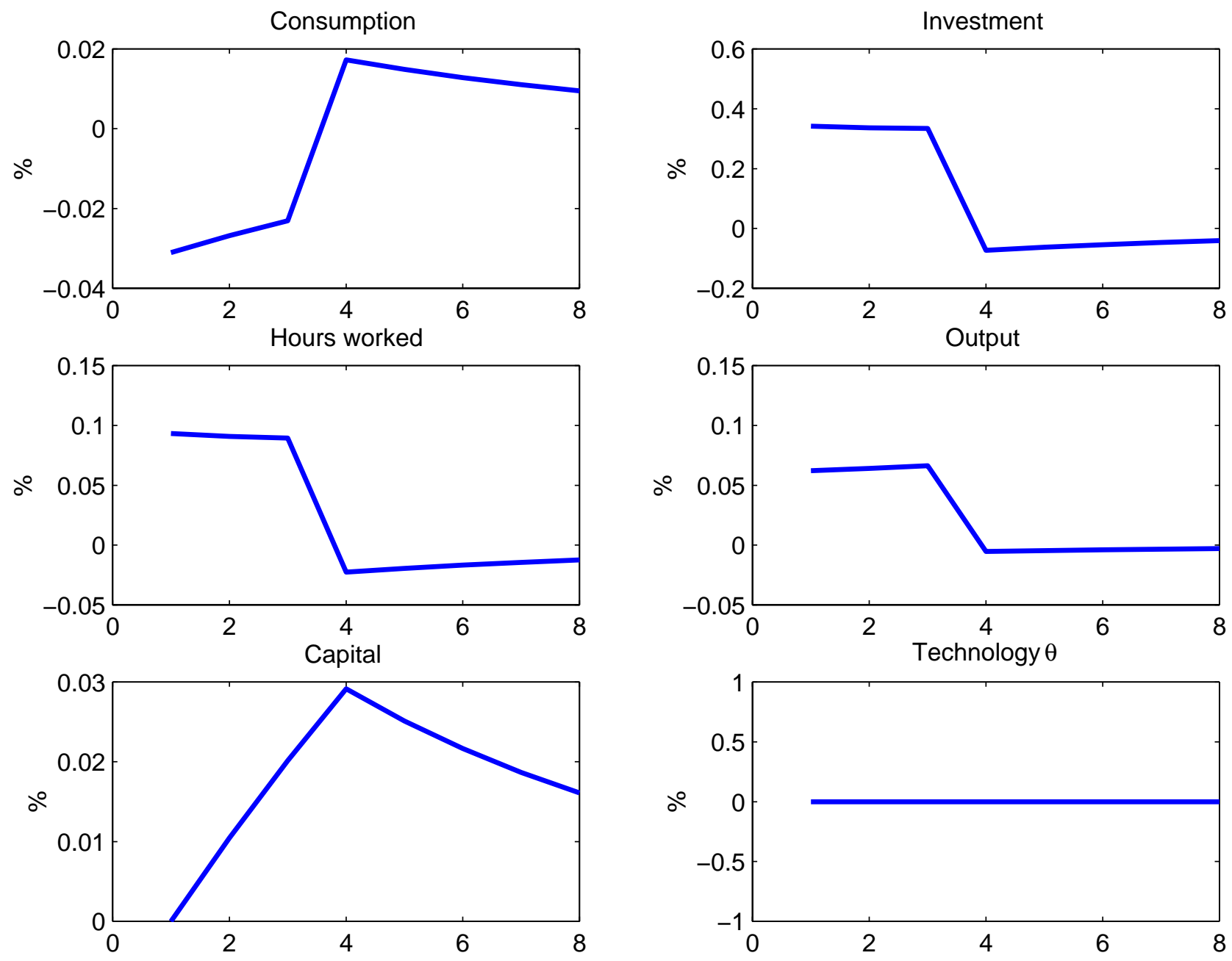
Figure 3: Response of the two-sectors economy to an announcement at time 1 of future positive shock on $\theta_{k}$ or $\theta_{c}$ and no realization of that shock at time 4
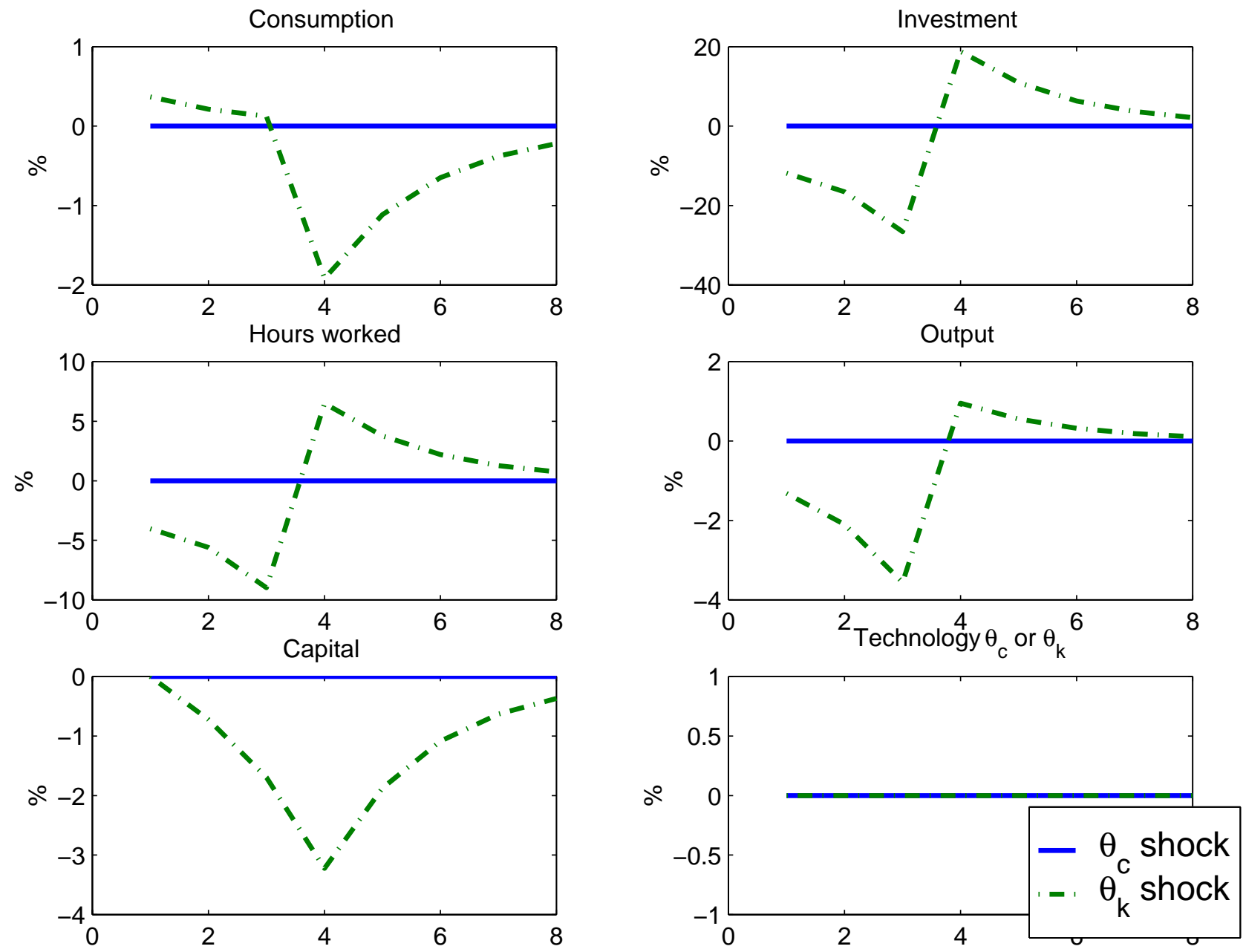
Figure 4: Response of the two-sectors economy to an announcement at time 1 of future positive shock on $\theta_{c}$ and no realization of that shock at time 4
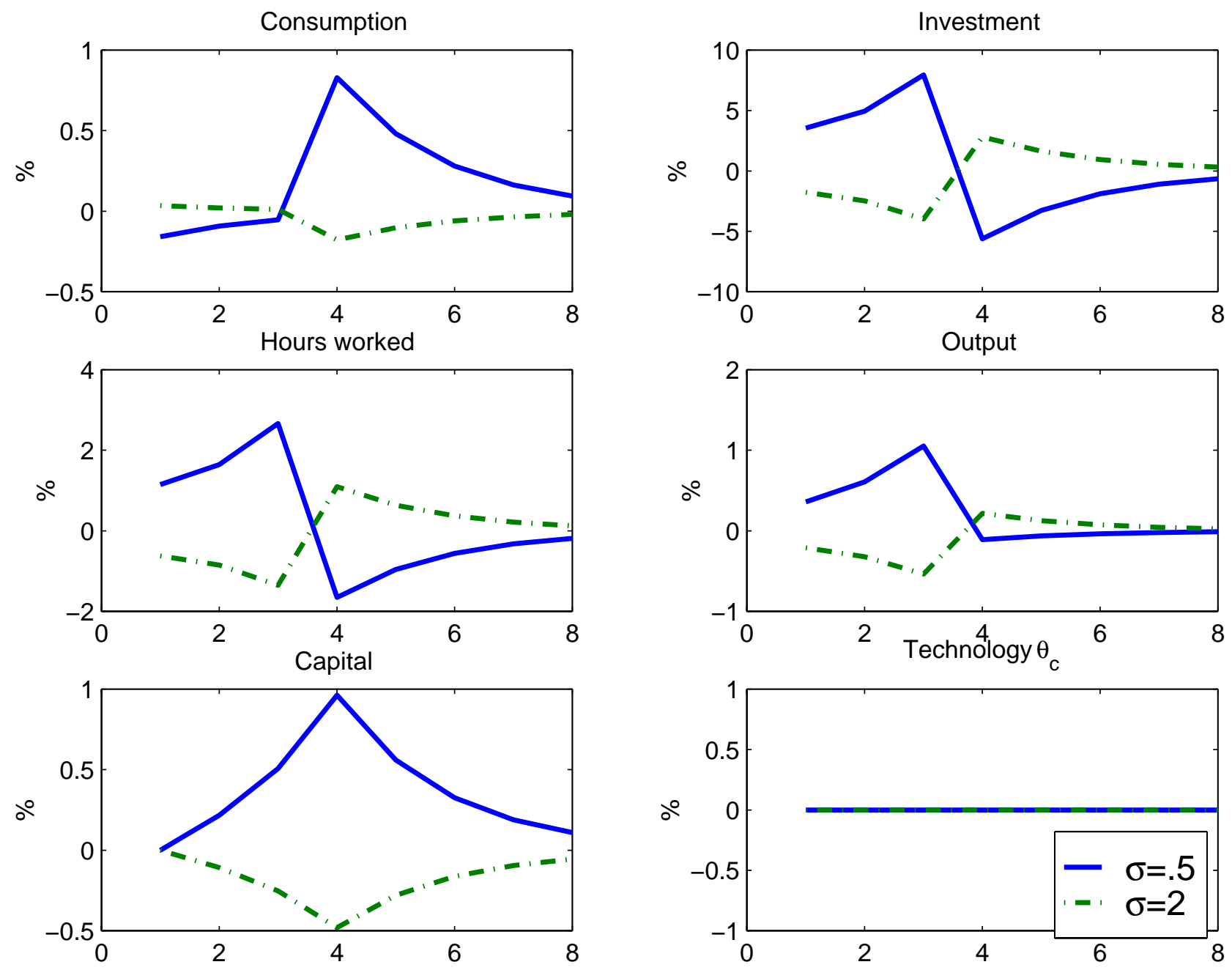


\section{Figures related to Section 4}

Figure 5: Transitional dynamics with $K_{0}$ below steady state (all variables are measured in relative deviations from their respective steady-state level)
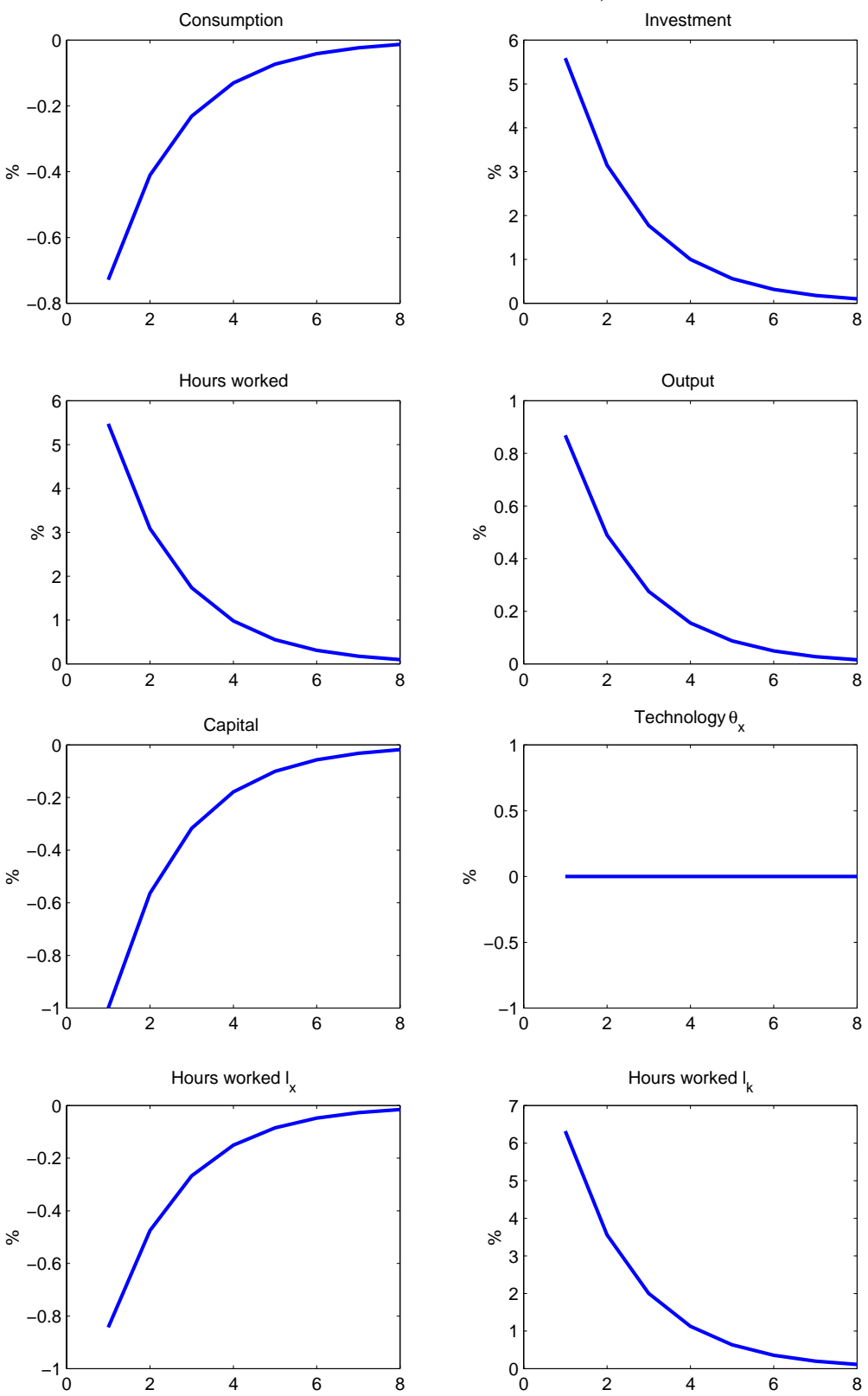
Figure 6: Response of the three-sectors economy to an announcement at time 1 of future positive shock on the technology and a realization of that shock at time 4
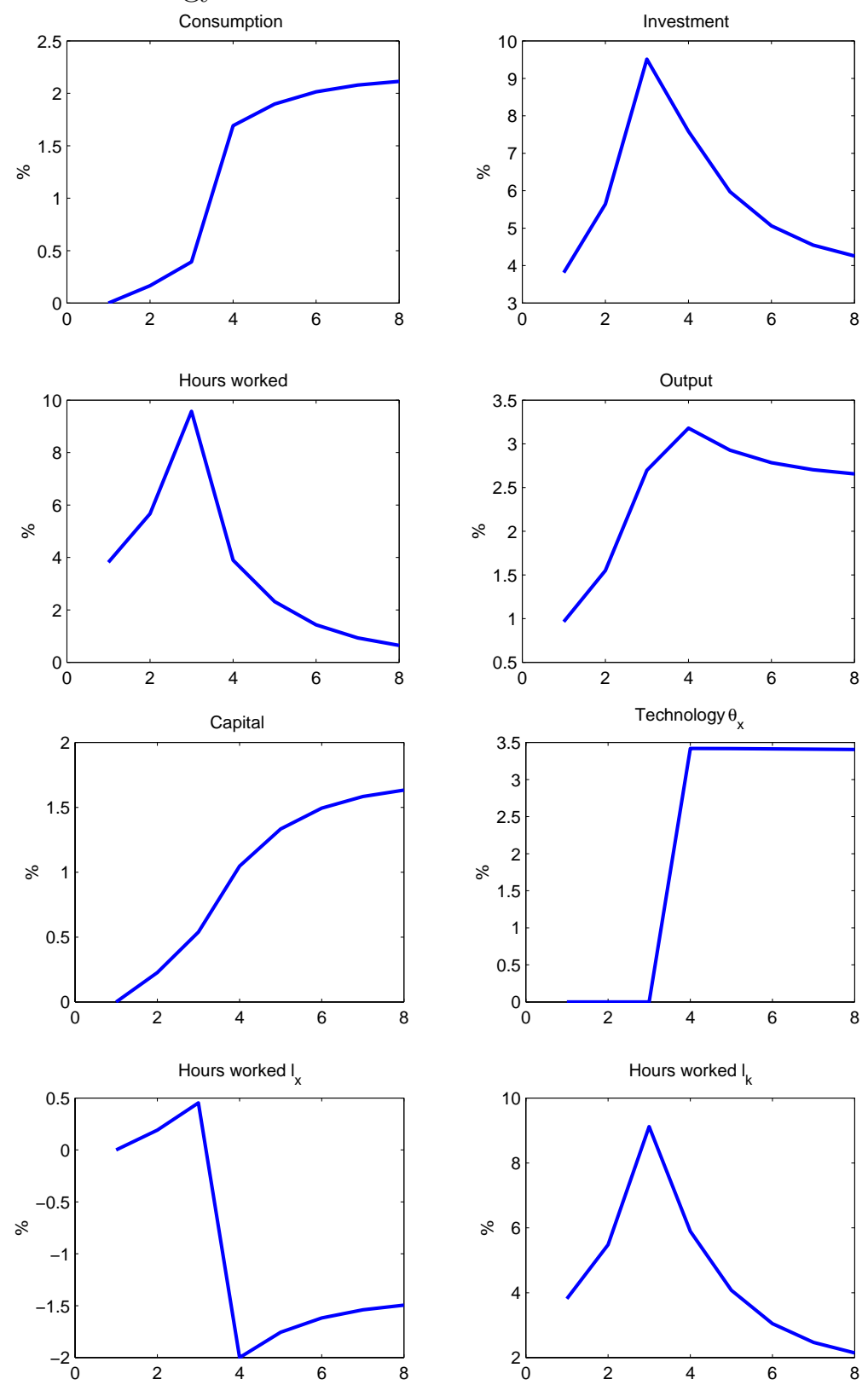
Figure 7: Response of the three-sectors economy to an announcement at time 1 of future positive shock on the technology and no realization of that shock at time 4
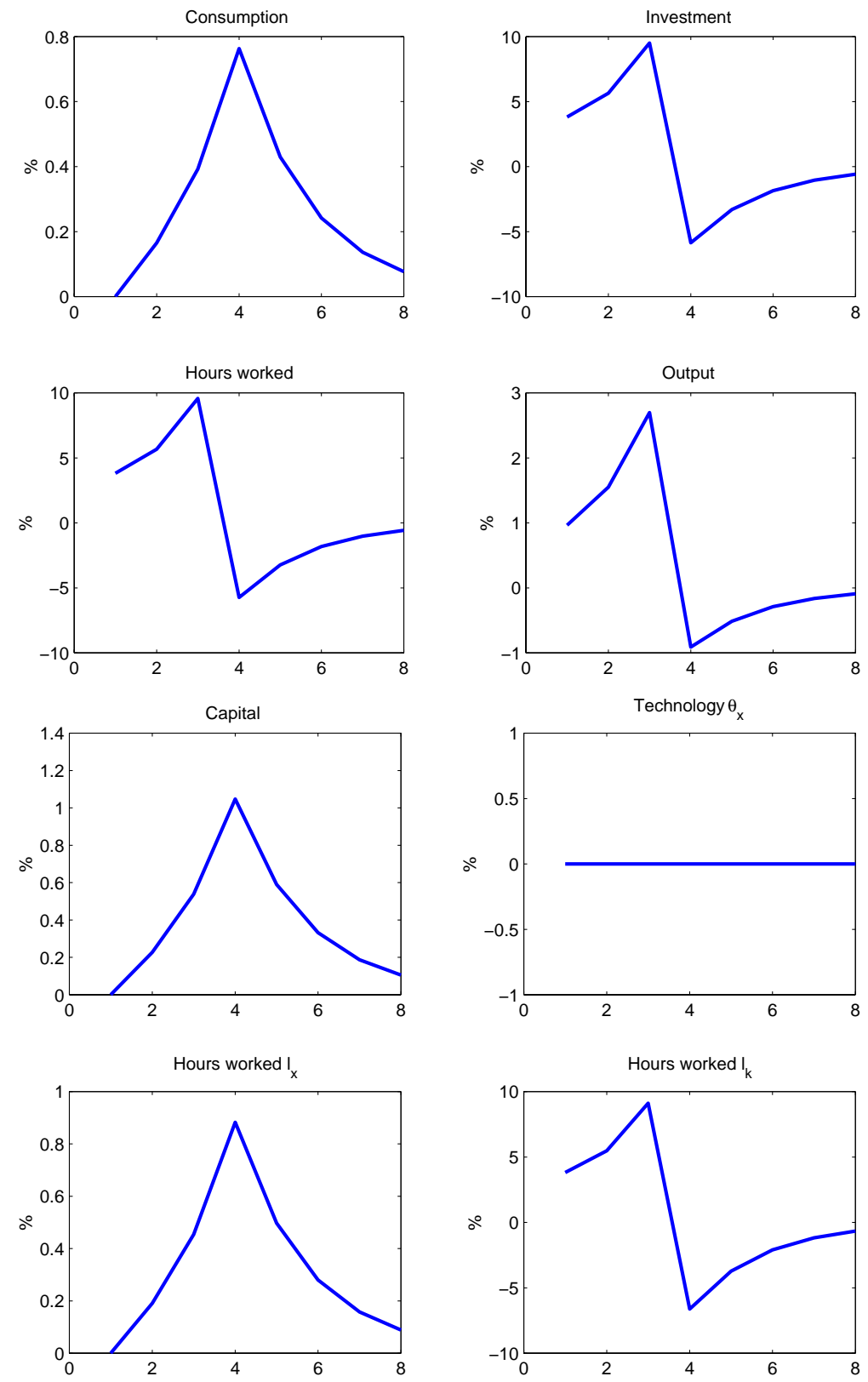
Figure 8: The Behavior of Investment Price in a Pigou Cycle

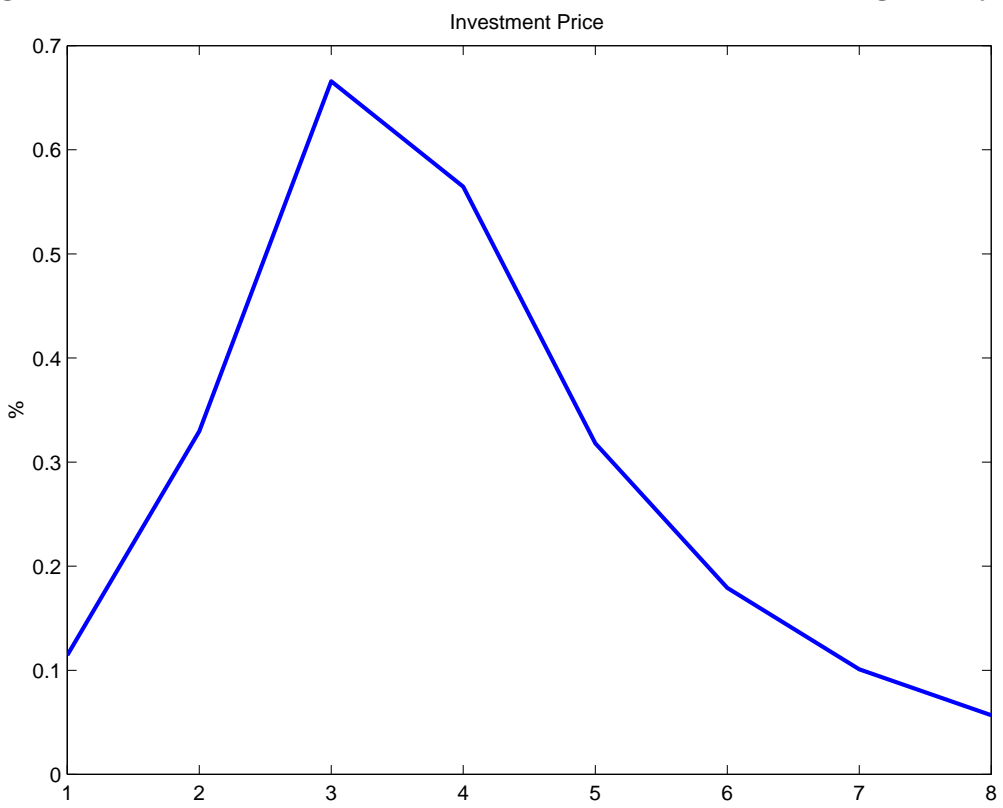

Figure 9: Output Growth Histogram

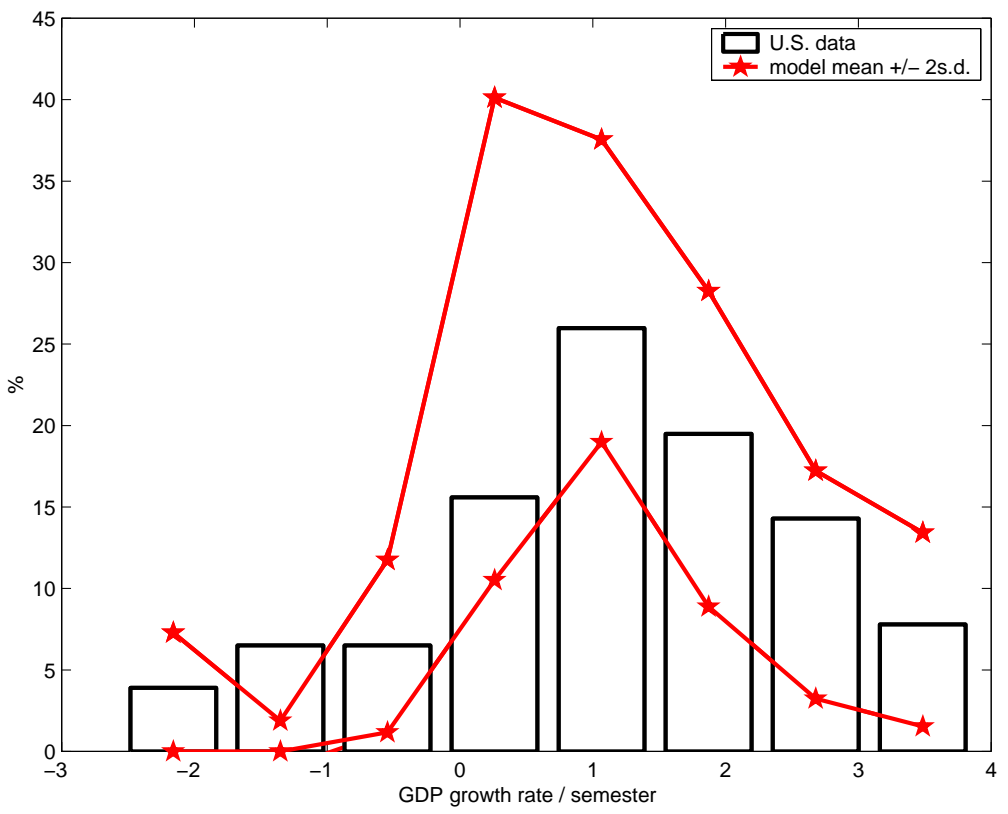




\section{Figures related to Section 5}

Figure 10: Asset Prices Responses to a Permanent Shock to Output

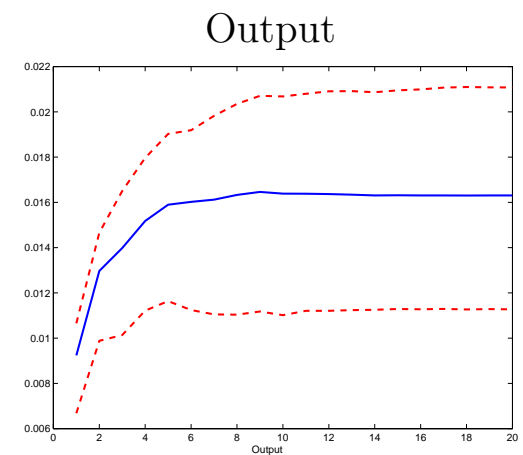

Output

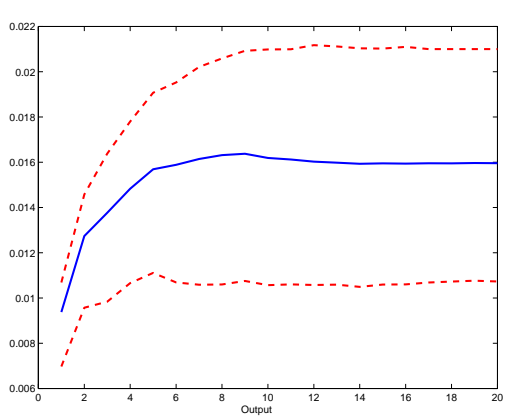

Output

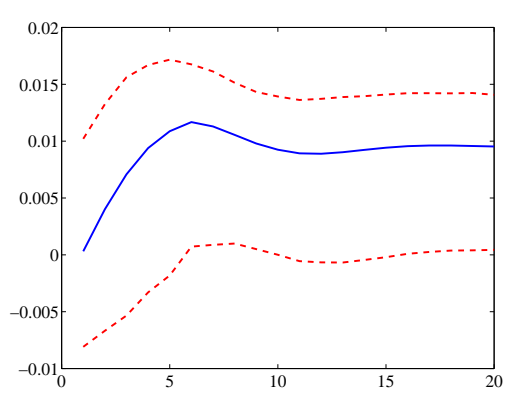

Residential Investment Price

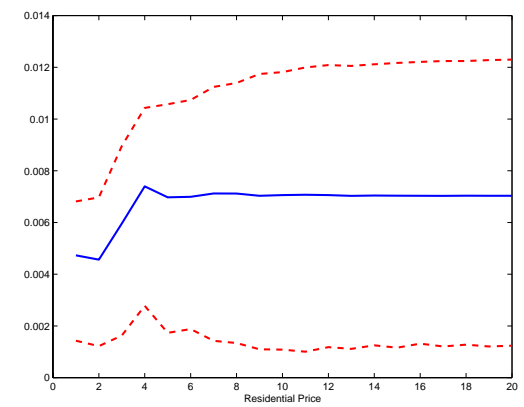

Nonresidential Buildings Price

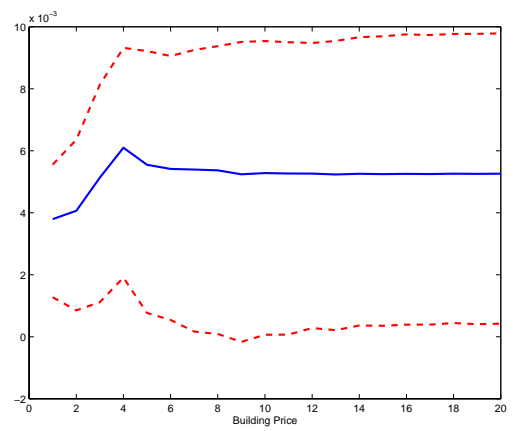

Stock Price

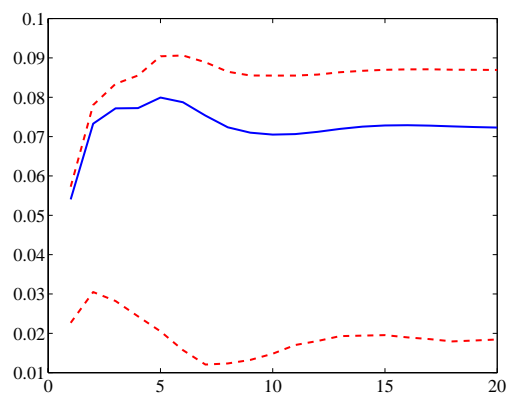

